\title{
THE MEDICAL AND SOCIAL IMPACT OF THE DISEASE IN PATIENTS WITH PSORIATIC ARTHRITIS
}

\author{
Tatiana ROTARU ${ }^{1}$, Natalia LOGHIN-OPREA ${ }^{\bowtie}$, Lucia MAZUR-NICORICI ${ }^{2}$, \\ Virginia SALARU ${ }^{3}$, Maria GARABAJIU ${ }^{3}$, Victoria SADOVICI-BOBEICA ${ }^{2}$, \\ Minodora MAZUR ${ }^{2}$
}

${ }^{1}$ Public Medical Sanitary Institution Institute of Cardiology, Chisinau, Republic of Moldova

${ }^{2}$ Department of Internal Medicine, State University of Medicine and Pharmacy "Nicolae Testemitanu", Chisinau, Republic of Moldova

${ }^{3}$ Department of Family Medicine, State University of Medicine and Pharmacy "Nicolae Testemitanu", Chisinau, Republic of Moldova

Received 20 July 2021, Accepted 17 Aug 2021

https://doi.org/10.31688/ABMU.2021.56.3.04

\section{Abstract}

Introduction. Psoriatic arthritis (PsA) is chronic disease associated with considerable psychological burden and impaired quality of life (QoL).

The objective of the study was to determine the medical and social status of patients with PsA, to optimize the management of these patients and increase their QoL.

Material and methods. We performed a cross-sectional study in which were included patients with PsA. Demographic and clinical data were collected using a special questionnaire, including employment and profesional status, information related to disease onset and duration, clinical overview related to the disease. In order to appreciate the burden of PsA, we applied the Rankin's scale, Health Assessment Questionnaire (HAQ), Short Form 8 (SF-8), Work Productivity and Activity Impairment (WPAI) and Disease Activity score in Psoriatic Arthritis (DAPSA), Patient Global Assessment (PGA) to assess the disease activity.

\section{Résumé}

L'impact médical et social de la maladie sur les patients atteints d'arthrite psoriasique

Introduction. L'arthrite psoriasique (APs) est une maladie chronique associée à un fardeau psychologique considérable et à une altération de la qualité de vie (QdV).

L'objectif de l'étude a été de déterminer le statut médical et social des patients atteints d'APs afin d'optimiser leurs prise en charge et d'augmenter leur QdV. Matériel et méthodes. Nous avons réalisé une étude transversale, dans laquelle des patients atteints d'APs ont été inclus. Les données démographiques et cliniques ont été recueillies à l'aide d'un questionnaire spécial, comprenant l'emploi et le statut professionnel, des informations concernant le diagnostic et à la durée de la maladie, le tableau clinique de la maladie. Pour apprécier la charge de l'APs nous avons appliqué l'échelle de Rankin, Health Assessment Questionnaire tool (HAQ), Short Form-8 (SF-8), Work Productivity 
Results. 92 PsA patients were enrolled in the study. Male to female ratio was 1.09:1, the patient's mean age was $48.53 \pm 11.42$ years. According to DAPSA, patients had moderate to high disease activity. $34.78 \%$ of patients from the group of study were full-time employees. The assessment of work productivity by WPAI determined a level of absenteeism of $9.39 \pm 11.79 \%$ and presenteeism of $37.57 \pm 27.31 \%$. The QoL in PsA patients was diminished in both mental and physical domains; the average HAQ score value was 0.61 , which indicates a moderate functional status. According to Rankin's scale, the most frequent degree was the $2^{\text {nd }}$, found in 32 (34.78\%) patients.

Conclusions. Patients with PsA have medium/low medical and social status, caused by low physical functionality and psychological problems. To optimize the management of patients with PsA, it is necessary to integrate rheumatological, dermatological, psychological and social services.

Keywords: psoriatic arthritis, disability, medical and social status.

\section{List of abbreviations}

CASPAR - Classification Criteria for Psoriatic Arthritis

DAPSA-Disease Activity score in Psoriatic Arthritis

HAQ - Health Assessment Questionnaire tool

HLA - Human Leukocyte Antigen

OMERACT - Outcome Measures in Rheumatology

PGA - Patient Global Assessment

PsA - Psoriatic arthritis

QoL - quality of life

SF-8 - Short Form 8

SF-36 - Short Form 36

VAS - Visual Analogue Scale

WPAI - Work Productivity and Activity Impairment

\section{INTRODUCTION}

Psoriatic arthritis (PsA) is a chronic inflammatory arthritis associated with psoriasis; it shares many clinical features with other spondyloarthropathies and also rheumatoid arthritis. The clinical manifestations are variable and can change over time, evolving from one articular pattern to another. There is a considerable financial and psychological burden associated with this disease. Recently, significant progress in understanding the disease pathogenesis was done, that has translated into new therapies ${ }^{1}$.

The epidemiology of PsA is heterogeneous and has a wide variation amongst various population groups. It has been estimated to have a prevalence of $0.05 \%$ to $0.25 \%$ in the general population and and Activity Impairment (WPAI) et Disease Activity score in Psoriatic Arthritis (DAPSA), Patient Global Assessment (PGA) pour évaluer l'activité de la maladie.

Résultats. 92 patients atteints d'APs ont été inclus dans l'étude. Le rapport homme/femme était de 1,09:1, l'âge moyen des patients était de 48,53 $\pm 11,42$ ans. Selon le DAPSA, les patients présentaient une activité de la maladie modérée à élevée. Un total de 34.78\% des 92 patients ont étés employés a à temps plein. L'evaluation de la productivité du travail par

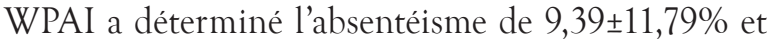
le présentéisme de 37,57士27,31\%. La QdV des patients était diminuée dans les domaines mental et physique; la valeur moyenne du score HAQ était de 0,61, ce qui indique un état fonctionnel modéré. Selon l'échelle de Rankin, le degré le plus fréquent était le 2e, trouvé chez 32 (34.78\%) patients.

Conclusions. Les patients atteints d'Aps ont un statut médical et social moyen/bas, causé par une faible fonctionnalité physique et des problèmes psychologiques. Pour optimiser la prise en charge des patients atteints d'APs il est nécessaire d'intégrer des services rhumatologiques, dermatologiques, psychologiques et sociaux.

Mots-clés: arthrite psoriasique, invalidité, statut médical et social.

around $6 \%$ to $41 \%$ in psoriasis patients ${ }^{1,2}$. The genetic epidemiology of PsA also supports its unique status. PsA has been associated with human leukocyte antigen (HLA) class 1 alleles. The epidemiological data available in the literature reveals that the age at the onset of the disease varies between 30 and 55 years, which means it involves population with active age, in terms of professional, personal and family activities ${ }^{3,4}$. Regarding gender distribution, the researchers found that PsA can equally affect both women and men ${ }^{5}$. The diagnosis and classification of PsA is based on a validated set of criteria proposed by Classification Criteria for Psoriatic Arthritis (CASPAR) group ${ }^{6}$.

Several clinical features allow the differential diagnosis of PsA from other types of arthritis, including rheumatoid arthritis (RA). The specific clinical 
features include joint involvement of the distal joints in PsA. Although the level of pain detected by Visual Analogue Scale (VAS) is different between patients with PsA and RA, the scores of Health Assessment Questionnaire (HAQ) identified in clinical trials are similar for both diseases? ${ }^{7}$. One of the most possible explanations is that the presence of enthesitis makes the difference. At the same time, the extra-articular manifestations of PsA are also different: the rheumatoid nodules are absent, and the rheumatoid factor is found in only $13 \%$ of patients with PsA ${ }^{1}$. Moreover, PsA is classified as spondyloarthritis due to the presence of spondylitis in up to $40 \%$ of patients, the appearance of common extra-articular manifestations (mucosal lesions, iritis, urethritis, diarrhoea, aortic root dilation) and association with HLA-B27 $7^{2,5}$.

The impact of the disease in patients with PsA, assessed through the quality of life (QoL) and functional capacity, is significant when compared to patients with isolated skin psoriasis or healthy subjects ${ }^{8}$. The assessment of the QoL using the Short Form 36 (SF 36) questionnaire showed significant differences between patients with PsA and general population?. The QoL assessed by SF-36 questionnaire, as well as the functional status analyzed by HAQ, correlated with the disease duration and its severity, with a decrease of these indices in parallel with the progression of PsA ${ }^{7,9}$. The burden of skin damage and joint inflammation is considerable in PsA, the disease negatively affects the work productivity, leading to high rates of healthcare services use $\mathrm{e}^{10-12}$. As a consequence, the evolution of PsA is associated with disability and decreased QoL. PsA is also associated with increased medical costs and loss of work productivity as the severity of the disease increases. In PsA, the two chronic conditions that affect both the skin and the joints can lead to both functional and cosmetic problems. Similarly, compared to psoriasis, PsA is associated with decreased QoL, and patients with PsA have a more advanced dysfunction and disability than those with psoriasis ${ }^{4,8,11}$. The presence of comcomitant psoriasis can increase the impact of the disease, as they can cause significant physical, psychological, social consequences and disability ${ }^{13}$.

An important aspect that affects the QoL and the financial status of a patient with PsA is the work disability, assessed by absenteeism and presenteeism. The review of related medical literature resulted in detailed data on disability and validity of measuring instruments in rheumatic conditions, such as rheumatoid arthritis and ankylosing spondylitis, but to date there are few data available for PsA ${ }^{13,14}$. The World Health Organization defines disability as deficiencies, activity limitations and participation restrictions; it is not just a health issue, but a complex phenomenon that reflects the interaction between the person's body features and the characteristics of the society in which he lives ${ }^{15}$.

Regarding the medical-social status of patients with PsA, we found limited data in the literature, that was mainly focused on the research of isolated skin psoriasis $^{3,6,13}$.

The obJective OF THE STUDY was to determine the medical and social status of patients with PsA in order to optimize the management of these patients and increase their QoL.

\section{Material AND MEthods}

We have conducted a cross-sectional study; the results presented in this paper are part of a greater research, approved by the Ethical committee of Public Medical Sanitary Institution Institute of Cardiology, Chisinau, Republic of Moldova, no 1 from 28.12.2012. The period of the study was January 2016 to December 2019. The criteria for inclusion in the study were adult patients diagnosed with PsA, who signed an informed consent for participation. The exclusion criteria were arthritis of another etiology and the refusal of the subject. Clinical and demographic data were collected, including information about the onset and duration of the disease, employment status and profession, level of education, and also functional status. The activity level of PsA was quantified by the specific instrument - Disease Activity score in Psoriatic Arthritis (DAPSA) and Patient Global Assessment (PGA) ${ }^{16}$. The DAPSA was interpreted from 0-4 remission; 5-14-reduced disease activity; 15-28-moderate activity and $>28$ - high activity. The overall assessment by the patient - PGA was determined by VAS containing values from 0 to 100 $\mathrm{mm}^{17}$. The degree of functional disability at the time of the research was assessed by applying the modified Rankin scale with possible scores 0 -no disability, 1-no significant disability despite symptoms that do not interfere with patients' daily activity, 2-mild disability or inability to perform all previous activities, but the patient can take care of himself without help, 3-moderate disability, symptoms significantly limit the patient's normal activities and prevent him from having a completely independent life, 4-moderate-severe disability, manifested by the inability to have a life independent, but does not require permanent care, 5-severe disability with immobilization in bed, totally dependent requiring permanent care ${ }^{18}$. Regarding the professional situation, the employment status at the time of the assessment was considered and classified as follows: full-time, part-time, unemployed and disabled, according to the degree of disability based on 
the criteria in Republic of Moldova. According to the proposed objective, to assess labour productivity, we applied the questionnaire on work productivity and limitation of general health activity (WPAI:PsA) version 2.0, which contains 6 questions, resulting in the calculation of four indices: absenteeism, presenteeism, work productivity and daily activity limitations ${ }^{19}$. The QoL was determined by applying the self-administered SF-8 questionnaire with two domains: physical and mental ${ }^{10}$. The assessment of physical functionality was performed through the HAQ tool, the total score can be in the range 0-3.0; a higher score indicates poorer performance ${ }^{20}$. The study was conducted in accordance with the Helsinki Declaration on Human Rights. The statistical analysis of the obtained data was performed with the MedCalc v.1.2 and Excel program, the arithmetic mean and the standard deviation were calculated. The degree of correlation was calculated by the Pearson test, where $r \geq 0.6$ was estimated as strong correlation. The statistical significance was considered for $\mathrm{p}$ values $\mathrm{p}<0.05$.

\section{Results}

The study included 92 consecutive patients with PsA who met the pre-established inclusion and exclusion criteria. The demographic parameters of the subjects are presented in Table 1 .

Of particular interest was the estimation of disease progression over time, data related to the duration of the disease (Table 2).

Another important aspect in the evaluation of patients with PsA was the assessment of disease activity. The level of PsA activity determined by the

Table 1. Demographic data of patients in the group of study.

\begin{tabular}{ccc}
\hline Variables & $\begin{array}{c}\text { Patients with } \\
\text { PsA, } n\end{array}$ & $\begin{array}{c}\text { Patients with } \\
\text { PsA (\%) }\end{array}$ \\
\hline Sex & & \\
Women & 44 & 47.83 \\
Men & 48 & 52.17 \\
\hline Marital status & & \\
Married & 76 & 82.61 \\
Divorced & 9 & 9.78 \\
Bachelor & 7 & 7.61 \\
\hline Level of education, years & & \\
$<9$ & 4 & 9.78 \\
$9-12$ & 48 & 52.17 \\
$>12$ & 40 & 38.05 \\
\hline Type of employment & & \\
Full time & 32 & 34.78 \\
Entrepreneur & 20 & 21.74 \\
Unemployed & 11 & 11.96 \\
Household & 13 & 14.13 \\
Retirees & 16 & 17.39 \\
\hline
\end{tabular}

physician was assessed by DAPSA and from the patient's perspective by PGA. When applying DAPSA, we determined a medium-high degree of disease activity, with a mean value of $23.04 \pm 7.41$ points, varying from 9.2 to 37.8 points. Patients with PGA self-administration assessed their disease activity by $59.22 \pm 14.65 \mathrm{~mm}$, which corresponds to a moderate level of activity.

The results obtained by applying the Rankin scale in the group of study are presented in Figure 1. The analysis of the disability status demonstrated that there were no patients without symptoms, 27 (29.35\%) patients scored a grade 1: no significant disability, symptoms did not interfere with normal daily activity, 32 (34.78\%) subjects had grade 2, which corresponds to a mild disability or inability to perform all previous activities, but with maintenance of the self-care function. A number of 14 (15.22\%) patients had moderate disability, the symptoms significantly restricted the daily activities, without having a completely independent life and $13(14.13 \%)$ patients had grade 4 after Rankin, manifested by the inability to have an independent life, but did not require permanent care. Severe disability with bed rest and need for permanent care, grade 5, was identified in $6(6.52 \%)$ patients. Grade 6 was not identified at the time of examination in the group of study.

The data concerning work productivity assessed by WPAI questionnaire in employed patients suggested that they were absent from work in the previous week - absenteeism, for $9.39 \pm 11.79$ hours (range 0 to 40 hours). Presenteeism, defined as loss of productivity during working hours, was estimated by $37.57 \pm 27.31$ hours of loss work productivity (range 4 to 32 hours. We have calculated the overall work productivity loss by WPAI, and it was determined in $23.87 \pm 23.90 \%$ of cases. With regard to the limitation of activity outside the workplace, it amounted to $56.09 \pm 26.72 \%$, with range $0-90 \%$. At the time of the research, 20 (21.74\%) patients were retired based on the degree of disability according to national disability criteria; of them, 2 had

Table 2. Clinical-demographic parameters of patients from the group of study.

\begin{tabular}{ccc}
\hline $\begin{array}{c}\text { Evaluated } \\
\text { parameters }\end{array}$ & $\begin{array}{c}\text { Mean } \\
\text { value } \pm \text { SD }\end{array}$ & Range \\
\hline $\begin{array}{c}\text { Mean age } \\
\text { at the time of study, } \\
\text { years }\end{array}$ & $48.53 \pm 11.42$ & $18-70$ \\
\hline $\begin{array}{c}\text { Mean duration } \\
\text { of the disease, } \\
\text { months }\end{array}$ & $179.78 \pm 137.87$ & $18-522$ \\
\hline $\begin{array}{c}\text { Time from onset } \\
\text { of arthritis, } \\
\text { months }\end{array}$ & $32.25 \pm 38.15$ & $11-118$ \\
\hline
\end{tabular}


grade I (severe), 10 grade II (moderate) and 8 grade III (minor) disability, according to local regulations.

Figure 2 shows the distribution of QoL, that demonstrates an involvement of the mental and physical components. The estimated average score of the physical component was 40.79 (range 18 to 62), and the average mental score was 43.04 (range 25 to 58), interpreted as reduced $\mathrm{QoL}$ in patients with PsA.

The analysis of the results of HAQ questionnaire revealed that the mean value was $0.61 \pm 0.48$, with wide variational ranges, from 0 to 1.4 points. We were interested in the hypothesis of correlating the HAQ score with the level of pain and number of affected joints. In the group of study, the pain was quantified by applying the VAS, and we established a mean score of $54.87 \pm 19.66 \mathrm{~mm}$, which corresponds to a moderate degree of pain. When assessing the number of joints affected, we found a mean value of $9.96 \pm 10.02$, the number of swollen joints being $3.87 \pm 4.73$.

\section{Rankin scale}
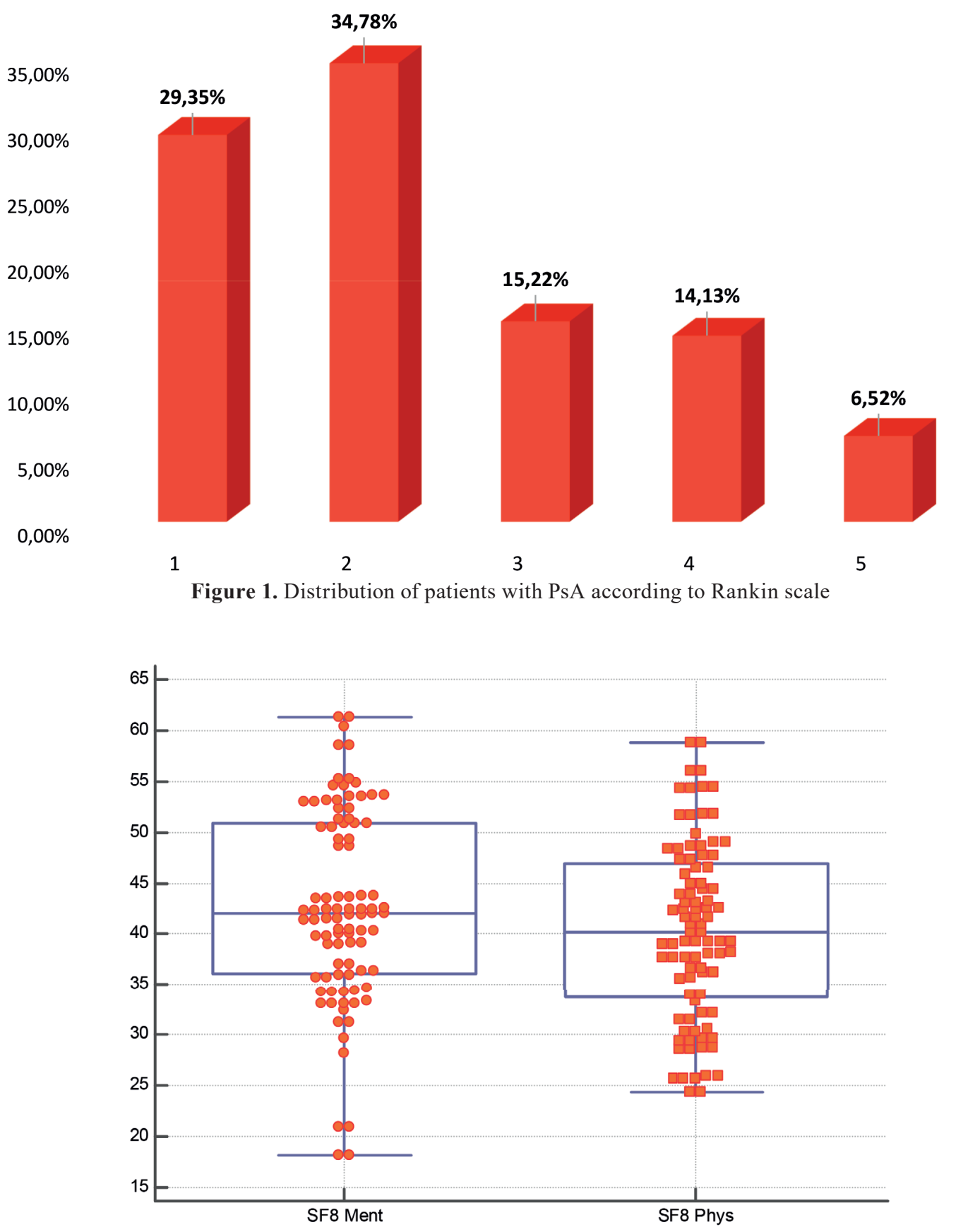

Figure 2. Box-plot analysis of QoL in patients with PsA. 
Subsequently, we were interested in establishing reciprocal relations where several variables were analyzed, and the results are summarized in Table 3 . The close correlation between the number of painful, swollen joints and pain is obvious. There is also a moderate correlation between the Rankin disability scale and HAQ functionality.

\section{Discussion}

PsA has been described as a dynamic balancing and iterative process that requires patients to redefine what is considered normal life during their illness. In particular, the increased symptoms of pain, fatigue and stiffness result in patients paying more attention to how they are affected by the disease and making efforts to alleviate the symptoms of the disease ${ }^{21}$.

PsA is a substantial burden on patients, by diminishing their QoL and reducing their ability to perform daily activities. We compared the results of our study with those available in the literature regarding the importance of medical and social conditions, intellectual and habitual stress related to rheumatic diseases, including PsA. The epidemiological data in our group of study was similar to the results of a Spanish study, which has found that PsA occurs with a similar frequency in both sexes ${ }^{23}$. Also, the patients in our group of study with an educational level of 9 years were a minority, most subjects (about half) were those with studies between 9 and 12 years, and higher education associated with postgraduate studies in $38.05 \%$ of cases. We compared our data with a study conducted by Eder et al., in which the educational level was also appreciated, and reported the predominance of patients with high educational level, $71.7 \%$ versus $38.05 \%$ in our study ${ }^{5}$. Moreover, these authors concluded that a lower educational level is a reserved prognostic factor for the disease ${ }^{5}$.
In our study, patients with PsA had varying degrees of disability according to the Rankin scale. In fact, in the case of $1 / 3$ of patients with PsA, the average degree of disability that correlated with the HAQ functionality score was determined, being a unique finding, given that this clinical tool was previously applied to patients with PsA in small groups, with non-statistically significant data.

Regarding the physical functionality assessed by HAQ, the literature data show various results. A meta-analysis performed by Lee et al. presents scores that ranged from 0.58 to $1.25^{13}$; the results obtained in our study fall within this wide range. Eder et al. found in their research a HAQ score of 0.34 , meaning a good physical functionality ${ }^{5}$.

The last decade has seen a rapid development of outcome measures in PsA. Measures for disease activity in individual key areas, inclusive arthritis, skin, enthesitis and dactylitis, have been validated ${ }^{16}$. A new aspect, according to Outcome Measures in Rheumatology (OMERACT) group, becomes the mandatory assessment of QoL in patients with $\mathrm{PsA}^{22}$. To assess the psychosocial burden in patients with PsA, there are validated clinical tools, such as the evaluation of the QoL through the mental and physical components of SF-36 and its modification-SF-814,16. It is also important to interview the subject, as patients may minimize or aggravate the answers in the paper questionnaires. It is necessary to monitor the patient's movements to detect possible functional problems that cannot be obtained verbally. Collateral information from family and friends may also be valid, such as minimized depression, anxiety, or psychosocial stress ${ }^{10,13}$.

The obtained results reveal low scores and reduced QoL in both areas. These data are consistent with data from the literature. Gratacos et al. have found $37.9 \pm 10.9$ and $46.9 \pm 12.6$ for the physical and

Table 3. The results of the correlative analysis of the main indices in PsA.

\begin{tabular}{|c|c|c|c|c|c|c|}
\hline Parameters & Rankin scale & SF-8 phys & HAQ & NPJ & NSJ & VAS \\
\hline Rankin scale & $\ldots$ & $\begin{aligned} r & =0.4 \\
p & =0.01\end{aligned}$ & $\begin{array}{l}r=0.58 \\
p=0.01\end{array}$ & $\begin{array}{l}r=0.36 \\
p=0.05\end{array}$ & $\begin{array}{l}r=-0.45 \\
p=0.02\end{array}$ & $\begin{array}{l}r=0.45 \\
p=0.01\end{array}$ \\
\hline SF-8 & $\begin{array}{c}r=0.4 \\
p=0.01\end{array}$ & ...... & $\begin{array}{c}r=-0.39 \\
p=0.05\end{array}$ & $\begin{array}{l}r=0.39 \\
p=0.05\end{array}$ & $\begin{array}{l}r=0.42 \\
p=0.05\end{array}$ & $\begin{array}{l}r=0.43 \\
p=0.03\end{array}$ \\
\hline HAQ & $\begin{array}{l}r=0.58 \\
p=0.01\end{array}$ & $\begin{array}{c}r=-0.39 \\
p=0.05\end{array}$ & $\ldots$ & $\begin{array}{l}r=0.34 \\
p=0.05\end{array}$ & $\begin{array}{l}r=0.31 \\
p=0.05\end{array}$ & $\begin{aligned} r & =0.5 \\
p & =0.01\end{aligned}$ \\
\hline NPJ & $\begin{array}{l}r=0.36 \\
p=0.05\end{array}$ & $\begin{array}{l}r=0.39 \\
p=0.05\end{array}$ & $\begin{array}{l}r=0.34 \\
p=0.05\end{array}$ & $\ldots$ & $\begin{array}{c}r=0.73 \\
p<0.0001\end{array}$ & $\begin{aligned} r & =0.63 \\
p & =0.001\end{aligned}$ \\
\hline NSJ & $\begin{array}{l}r=-0.45 \\
p=0.02\end{array}$ & $\begin{array}{l}r=0.42 \\
p=0.05\end{array}$ & $\begin{array}{l}r=0.31 \\
p=0.05\end{array}$ & $\begin{array}{c}r=0.73 \\
p<0.0001\end{array}$ & $\ldots$ & $\begin{array}{l}r=0.51 \\
p=0.01\end{array}$ \\
\hline VAS & $\begin{array}{l}r=0.45 \\
p=0.01\end{array}$ & $\begin{array}{l}r=0.43 \\
p=0.03\end{array}$ & $\begin{aligned} r & =0.5 \\
p & =0.01\end{aligned}$ & $\begin{array}{c}r=0.63 \\
p=0.001\end{array}$ & $\begin{array}{l}r=0.51 \\
p=0.01\end{array}$ & $\ldots$ \\
\hline
\end{tabular}

Legend: NPJ-number of painful joints; NSJ- number of swollen joints. 
mental components of the QOL, respectively ${ }^{23}$. In turn, Kavanaugh concludes that PsA negatively influence both the QoL of these patients and their productivity of work ${ }^{24}$, similar to our study. Kavanaugh et al. reported that PsA had a severe impact on the work productivity ${ }^{24}$. These authors identified that about one-third of patients with PsA (31.5\%) reported missing work in the last 12 months because of the disease ${ }^{24}$. Similarly, $31.6 \%$ of subjects reported that PsA had a negative impact on their ability to work full time ${ }^{24}$. In the same study, patients with PsA had difficulties in getting a job, keeping it or choosing a career ${ }^{24}$. In the study of Gratacos et al., $30 \%$ of patients reported that in the previous month they could not perform normal daily activities, and the mean number of days per month in which they could not perform daily activities was $12.8 \pm 10.7$, while during $9.0 \pm 7.1$ hours per day they felt unable to carry out their normal activities ${ }^{23}$. In addition, $21 \%$ of patients felt the need to seek help from friends/ family to perform the most common activities of daily living ${ }^{23}$. Regarding employment status, it was found that $55 \%$ were employed at the time of the study, $16 \%$ retired from work because of PsA, and $6 \%$ of patients changed jobs because of illness. The authors mention that the mean reduction of working hours per week was $0.8 \pm 3.3$, and the mean reduction of income per month was below $7.6 \pm 52.9$ euros/ patient ${ }^{23}$. We can conclude that PsA negatively influences both employee status and work productivity.

Because of the global impact of the disease and involvement of both skin and musculoskeletal system, patients with PsA have several challenges, that affect their physical, mental and social integration status. To improve their QoL, there is a need for a patient-centred and team-based approach. The integration of medical care that aims to improve joint function, reduce pain, and also to control rashes, together with support and social integration would be the necessary solutions to improve the $\mathrm{QoL}$ of these patients and improve treatment outcomes.

\section{Conclusions}

Patients with PsA have medium/ low medicosocial status, with a negative impact determined by the affected physical functionality, and also by the impact on mental health caused by social stigma induced by skin damage. This led to a decrease in work productivity, and also the phenomenon of social isolation. To optimize the management of patients with PsA, it is necessary to integrate rheumatological, dermatological, psychological and social services.

\section{Author Contributions:}

Conceptualization, M. M. and L.M.N.; methodology, N.L.O.; data curation, T.R.,M.G.; writing-original draft preparation, N.L.O., V.S.B.; writing-review and editing, M.M, N.L.O, V.S. All the authors have read and agreed with the final version of the article.

\section{Compliance with Ethics Requirements:}

"The authors declare no conflict of interest regarding this article"

"The authors declare that all the procedures and experiments of this study respect the ethical standards in the Helsinki Declaration of 1975, as revised in 2008(5), as well as the national law. Informed consent was obtained from all the patients included in the study"

"No funding for this study"

\section{Acknowledgements:}

None

\section{References}

1. Tiwari V, Brent LH. Psoriatic Arthritis. [Updated 2021 Aug 11]. In: StatPearls [Internet]. Treasure Island (FL): StatPearls Publishing; 2021 Jan-. Available from: https://www.ncbi. nlm.nih.gov/books/NBK547710/.

2. Dewing K. Management of patients with psoriatic arthritis. Nurse Pract. 2015;40(4):40-46

3. Husni M, Merola J, Davin S. The psychosocial burden of psoriatic arthritis. Semin Arthritis Rheum. 2017;47(3):351-360.

4. Truong B, Rich-Garg N, Ehst B, et al. Demographics, clinical disease characteristics, and quality of life in a large cohort of psoriasis patients with and without psoriatic arthritis. Clin Cosmet Investig Dermatol. 2015;(8):563-569.

5. Eder L, Haddad A, Rosen C, et al. The incidence and risk factors for psoriatic arthritis in patients with psoriasis: a prospective cohort study. Arthritis Rheumatology. 2016;68(4):915-923.

6. Mease P, Armstrong A. Managing patients with psoriatic disease: the diagnosis and pharmacologic treatment of psoriatic arthritis in patients with psoriasis. Drugs. 2014;74(4):423-441.

7. Helliwell P, Ruderman E. Natural history, prognosis and socioeconomic aspects of psoriatic arthritis. Rheum Dis Clin North Am. 2015;41(4):581-591.

8. Eder L, Gladman D. Predictors for clinical outcome in psoriatic arthritis-what have we learned from cohort studies? Expert Rev Clin Immunol. 2014;10(6):763-770.

9. Husted J, Gladman D, Farewell V, et al. Validating the SF-36 health survey questionnaire in patients with psoriatic arthritis. J Rheumatol. 1997;24(3):511-517.

10. Feldman S, Malakouti M, Koo J. Social impact of the burden of psoriasis: effects on patients and practice. Dermatol Online J. 2014;20 (8):13030/qt48r4w8h2.

11. Giacomelli R, Gorla R, Trotta F, et al. Quality of life and unmet needs in patients with inflammatory arthropathies: results from the multicentre, observational RAPSODIA study. Rheumatology (Oxford). 2015;54(5):792-797.

12. Boehncke W, Menter A. Burden of disease: psoriasis and psoriatic arthritis Am J Clin Dermatol. 2013;14(5):377-388. 
13. Lee S, Mendelsohn A, Sarnes E. The burden of psoriatic arthritis: a literature review from a global health systems perspective. PT. 2010;35(12):680-689.

14. Tillett W, Shaddick G, Askari A, al. Factors influencing work disability in psoriatic arthritis: first results from a large UK multicentre study. Rheumatology (Oxford). 2015;54(1):157-162.

15. https://www.who.int/topics/disabilities/en/ (accessed on 29 June, 2020)

16. https://rheuma.charite.de/fileadmin/user_upload/microsites/ohne_AZ/m_cc13/rheuma/Templates/DAPSA_ENG. pdf (accessed on 15 June, 2021)

17. Cauli A., Gladman, D, Mathieu A, et al. Patient Global Assessment in Psoriatic Arthritis: A Multicenter GRAPPA and OMERACT Study. J Rheumatol. 2011;38(5):898-903.

18. https://www.mdcalc.com/modified-rankin-scale-neurologic-disability (accessed on 11 June, 2021)

19. http://www.reillyassociates.net/WPAI_Scoring.html (accessed on 12 June, 2021)
20. Mease P, Strand V, Gladman D. Functional impairment measurement in psoriatic arthritis: Importance and challenges. Semin Arthritis Rheum. 2018;48(3):436-448.

21. Grønning K, Lomundal B, Koksvik H, Steinsbekk A. Coping with arthritis is experienced as a dynamic balancing process. A qualitative study. Clin Rheumatol. 2011;30(11):1425-1432.

22. Coates L. Outcome measures in psoriatic arthritis. Rheum Dis Clin North Am. 2015;41(4):699-710.

23. Gratacós, J, Daudén E, Gómez-Reino J, et al. Health-related quality of life in psoriatic arthritis patients in Spain. Reumatol Clin. 2014;10(1):25-31.

24. Kavanaugh, A, Helliwell P, Ritchlin, C. Psoriatic arthritis and burden of disease: patient perspectives from the population-based multinational assessment of psoriasis and psoriatic arthritis (MAPP) survey. Rheumatol Ther. 2016;3(1):91102. 